\title{
Plant bioclimatic models in climate change research
}

\author{
Chyi-Rong Chiou' ${ }^{1}$ Tung-Yu Hsieh ${ }^{2,3,4^{*}}$ and Chang-Chi Chien ${ }^{5}$
}

\begin{abstract}
Bioclimatics is an ancient science that was once neglected by many ecologists. However, as climate changes have attracted increasing attention, scientists have reevaluated the relevance of bioclimatology and it has thus become essential for exploring climate changes. Because of the rapidly growing importance of bioclimatic models in climate change studies, we evaluated factors that influence plant bioclimatology, constructed and developed bioclimatic models, and assessed the precautionary effects of the application of the models. The findings obtained by sequentially reviewing the development history and importance of bioclimatic models in climate change studies can be used to enhance the knowledge of bioclimatic models and strengthen their ability to apply them. Consequently, bioclimatic models can be used as a powerful tool and reference in decision-making responses to future climate changes. The objectives of this study were to (1) understand how climatic factors affect plants; (2) describe the sources, construction principles, and development of early plant bioclimatic models (PBMs); and (3) summarize the recent applications of PBMs in climate change research.
\end{abstract}

Keywords: Climate change, Phenological model, Theoretical model, Statistical model, Mechanistic model

\section{Background}

Bioclimatology or bioclimatics, which includes phenology, is an ancient science that investigates the relationship between living organisms and climates. According to historical records, China was the first country to conduct bioclimatic observation approximately 3,000 years ago. Bioclimatology is referred to as Wuhou (物候) in Chinese, a word that originated from the classic Ch'unch'iu Tso Chuan (春秋左傳). Western bioclimatology was established in approximately 1753 by Linnaeus, a Swedish botanist, who is known as the father of phenology. The term phenology was first introduced by the Belgian botanist Morren in 1853. One hundred years before the term was coined during Linnaeus' time, phenology was focused on the seasonal and periodic phenomena that organisms exhibit and is referred to as classic or seasonal bioclimatology. In Japan, phenology is referred to as the study of seasons and organisms. Scientists have since

\footnotetext{
*Correspondence: sdyhsieh@gmail.com

${ }^{2}$ Shanghai Institutes for Biological Sciences, Chinese Academy

of Sciences, 320 Yue Yang Rd., Shanghai 200031, China

Full list of author information is available at the end of the article
}

identified that changes in living organisms follow periodic changes in climates. Thus, the scope and definition of phenology vary constantly as new bioclimatic findings are obtained. Consequently, the early definition of phenology has become inapplicable. Although numerous scientists have attempted to redefine phenology and create linguistically specific technical terms, many people prefer to use the established term phenology, which has been used continuously since it was coined. Bioclimatology, including phenology, now involves investigations of the correlations between climates and organisms (Chu and Wan 1999; Hopkins 1938; Hsieh and Chiou 2013; Lieth 1974; Schnelle 1955; Zou 1983). To avoid confusion caused by different definitions, this article defines all types of model that have both biological and climatic variables as bioclimatic models.

Despite its ancient origin, bioclimatology has long been disregarded because of problems, such as difficulty in funding long-term research in the past. In recent years, bioclimatology has received increasing attention and has become critical for investigating the effects of climate changes on organisms (Hänninen and Tanino 2011; Hsieh and Chiou 2013; Körner and Basler 2010; Lechowicz and

\section{Springer}


Koike 1995). Initially, ancient people developed bioclimatology by recording the correlations between biological phenomena according to annual observations made during farming seasons and related experiences; in this way, lunar calendars and bioclimatic calendars were compiled. Thus, bioclimatic research development in ancient times was focused on agricultural phenomena and various biological indicators recorded in the bioclimatic calendars of different cultures were used as a disaster-prevention system for decision-making. Bioclimatology in the Western scientific field did not become a formal discipline until the mid-eighteenth century when Linnaeus established the first phenology observation networks in Sweden and emphasized the tasks and importance of phenological observations in his book Philosophia Botanica (Hsieh and Chiou 2013; Lieth 1974).

Because the threat of climate change has recently attracted increasing attention, phenology network records have been developed into two complementary research systems; one is the concept of bioclimatic fingerprints, which was developed from phenology observation networks and is used for observing and monitoring the effects of climate changes on organisms, and the other is bioclimatic modeling based on long-term bioclimatic records and variations of the phenology observation networks for clarifying the correlation between climates and organisms and predicting the possible effects of climate changes on organisms. The results can be used as references in future disaster alert systems, disaster-prevention decision-making, and the assessment of disaster effects (Peñuelas and Filella 2001).

Although bioclimatic models are essential to researching climate change effects and despite the rapid international development and application of bioclimatic models, research and reports regarding the application and exploration of bioclimatic models remain scant in many undeveloped and developing countries, which are severely threatened by climate change. To improve the capability of people to address the threat of climate changes, we reviewed the factors that influence plant bioclimatology, the construction and development of bioclimatic models, and the application of bioclimatic models in disaster prevention and impact assessment. The sequential review of the development history and importance of bioclimatic models in climate change research provided in this study can be used as references by researchers studying climate changes.

\section{Climatic factors that affect plant growth and development}

Bioclimatic models represent the phenomena, processes, or mechanisms of the effect of climate factors on organisms. Thus, before understanding the modeling principles of bioclimatic models, basic knowledge regarding the environmental factors that affect plant bioclimatology must be acquired. The effects of environmental factors on plants vary with plant species, phenological phases, geographical environments, physiological statuses, and levels and types of ecological systems, yielding complex mechanisms. Among numerous environmental factors, temperature, water availability, and air flow (i.e., wind) are more closely related to climate changes and substantially affect plants.

\section{Temperature}

The climatic conditions of different seasons and regions cause varying effects on the bioclimatology of different plants (Menzel et al. 2001). For example, the higher winter temperatures at middle latitudes cause most plants to blossom and sprout earlier (Sparkes et al. 1997). At middle and high latitudes, the end of growth periods and the beginning of dormant periods of most plants are primarily influenced by the shorter days and temperature conditions of late summer (Heide 1974; Wareing 1956). Subsequently, the low temperature of the following winter breaks plant dormancy (Fuchigami et al. 1982; Perry 1971; Vegis 1964). Fluctuating temperatures break plant dormancy more effectively than constant temperatures do (Campbell and Sugano 1975; Hänninen 1990; Murray et al. 1989). However for some plants, fluctuating and constant temperatures have the same effect (Myking 1997). Phenological variations during plant growth periods are primarily affected by accumulated temperature (Peñuelas and Filella 2001). However, selecting the initial temperature for calculating accumulated temperature has been a major difficulty in bioclimatology because it may differ substantially in plants of the same species when influenced by varying environmental factors (Heide 1993; Murray et al. 1989). This difference severely affects the precision and prediction accuracy in research regarding plant growth bioclimatology. Despite the differences, $5{ }^{\circ} \mathrm{C}$ is commonly used as the initial temperature for calculating the accumulated temperature of plants (Cannell and Smith 1986; Cannell et al. 1985; Kellomäki et al. 1995; Murray et al. 1989).

\section{Water availability}

In addition to temperature, water availability critically affects plant bioclimatology and is highly relevant to climate changes. However, the effects of water availability vary with species and other environmental conditions. In particular, the photoperiods and temperature conditions in tropical zones are relatively stable and variation in water availability is often the main factor influencing plant bioclimatology (Tissue and Wright 1995). For example, when it rains in tropical arid or semiarid 
climates, various plants blossom simultaneously, exhibiting high phenological synchrony (de Lampe et al. 1992). The following rainfall continuance affects the fruits of plants. A majority of tropical plants bear fruit in rainy seasons and the fruiting period is shortened or prolonged based on the precipitation of the current season (Bawa and Hadley 1991). Water shortage causes growth arrest among numerous plants, resulting in eco-dormancy (Reich and Borchert 1984). In high mountains and middle- to high-latitude areas, water availability and temperature changes resulting from thawing snow are key to plant blossom and growth (Walker et al. 1995).

\section{Airflow}

Airflow is also a critical climatic factor that affects plants. When daylight is sufficient, adequate airflow, such as a breeze or zephyr, facilitates the airflow exchange of leaves and promotes transpiration lowering the leaf and environmental temperatures. Airflow also assists the pollination of anemophilous plants; however, when the wind speed is excessively high, the photosynthesis of leaves is subdued; the stigmata of flowering plants dry up, which affects pollination and causes infertility; or soil drying and wind erosion are expedited, which results in exposed plant roots, fallen fruits, leaves, and flowers, and even severe mechanical injuries, such as broken and fallen stems. Consequently, trees are weakened because of malnutrition, diseases, pests, or infections, which cause alternate bearing, and eventually die from nutrition depletion (Campbell-Clause 1998; Duryea et al. 1996; Telewski 1995).

\section{Climatic factors in different growth and development stages}

The effects of climatic factors on plants differ according to the various growth and development stages of plants. For example, climate conditions influence germination so that the germinating of seeds of different species and in various regions differs substantially. The seeds of plants that grow in temperate latitudes require low temperatures or fluctuating temperature conditions that last for a certain amount of time to break dormancy (Hsieh et al. 2004). However, numerous studies have shown that some temperate plant species can break seed dormancy through exposure to high temperatures and long photoperiod days (Isikawa 1954; Johnson and Irgens-Moller 1964; Stearns and Olson 1958). Some temperate species can break dormancy and sprout only after exposure to a period of low temperature following exposure to high temperature, such as Taxus sumatrana (Miq.) deLaub. (Chien et al. 1995) and peony seeds. The germination of seeds from numerous species also varies with environmental conditions, such as those for Tsuga canadensis
L. The seeds of Tsuga canadensis L. break dormancy and germinate after exposure to 10 weeks of low temperature. However, the temperature required for germination of seeds that have not been exposed to low-temperature stratification increases with the length of photoperiod. For a general photoperiod of $8-12 \mathrm{~h}$, the optimal germination temperature ranges from 17 to $22^{\circ} \mathrm{C}$, Whereas if the length of the photoperiod is $16 \mathrm{~h}$, the optimal germination temperature increases to $27^{\circ} \mathrm{C}$ (Stearns and Olson 1958). However, Pseudotsuga menziesii (Mirb.) Franco seeds that have not undergone low-temperature stratification can successfully germinate after a short-photoperiod below $25{ }^{\circ} \mathrm{C}$ (Johnson and Irgens-Moller 1964). The climate requirements and resistance may differ even among the various organs of a plant species. A survey exploring the freeze injuries of Pyrus koehnei C.K. Schneid. showed that $90 \%$ of 6 -year-old plants were frozen to death under $-14{ }^{\circ} \mathrm{C}$ and $50 \%$ of suckers were frozen to death under $-12{ }^{\circ} \mathrm{C}$, whereas only $28 \%$ of stem surfaces exhibited freeze injury. The median lethal temperature of the different tissues ranged from -10 to $-15{ }^{\circ} \mathrm{C}$ (Nee et al. 1995).

\section{Climatic factors in different areas}

Climate changes may exert differing effects on the same species of plant in different areas with identical climatic conditions. For example, in certain areas of the former Soviet Union where the climatic conditions are identical, walnuts trees are frozen to death in autumn in certain locations but survive autumn in other places. A subsequent finding indicated that the difference is caused by varying photoperiods. In certain areas, the photoperiods shorten before the autumn frost, resulting in the early dormancy of walnuts. In other areas, the photoperiods are not short enough to induce bud dormancy. Therefore, with the same temperature during autumn frost, walnuts may be frozen to death in some areas but survive the frost in other areas (Haldane 1947). Photoperiods also influence the blossoming of strawberry flowers. Temperatures and photoperiods jointly regulate the differentiation of flower buds. Generally, long photoperiods imply that flower bud induction requires long durations at low temperatures whereas short photoperiods imply that flower bud induction requires short durations at low temperatures. Thus, in areas with the same temperature conditions, varying photoperiods may affect whether strawberry flowers blossom. The condition of the plant itself may also have an influence; for example, during flower bud induction, a decreased number of old leaves easily induces flower bud differentiation (Darnell and Hancock 1996).

Distinct microtopographies and microclimates influence precipitation; even a slight variation in rainfall may 
substantially affect plant growth. For example, at high altitudes, the fruiting amount of Actinidia is inversely proportional to the degree of overlap of flowering periods and the East Asian rainy season. A high degree of overlap implies low fruiting rates for a certain year, whereas a low degree of overlap increases the fruiting rate. Certain species lack fruit every year because the East Asian rainy season overlaps the flowering period. This severely affects the reproduction and growth of Actinidia. and damages economic growth related to the plants (Nee 1994). Moreover, plant species respond differently to climate changes. For example, if plants, such as Acer saccharum Marsh. and eastern hemlock, which originate from different regions, are planted at one location, the plants from the north areas or high altitudes stop growing early in the autumn (Nienstaedt and Olson 1961; Robak and Magnesen 1970). Altitudes also affect the temperature requirements and responses of plants. For example, the seeds and buds of Actinidia have different dormancy conditions at different altitudes. The higher the altitude, the higher the chilling requirement to break seed and bud dormancy (Fan and Nee 2007). By contrast, peach and cherry trees have lower chilling requirements at high altitudes (Huang 2011; Ou et al. 2000).

Based on the aforementioned research cases, we identified that understanding the physiological mechanisms through which climates affect plants is crucial to climate change research. The influence of climate changes on plants varies substantially with differences in species, region, and other influential factors. Therefore, if the physiological and ecological conditions of plants are not specifically controlled, constructing an appropriate bioclimatic model for climates with similar variable conditions and accurately evaluating and explaining the resulting influence of climate changes can be difficult.

\section{Bioclimatic model development}

The origin of plant bioclimatic modeling is earlier than the formal establishment of bioclimatology. Such models can be traced back to 1735, when Reaumur proposed that the bioclimatic events of organisms and the dates of occurrence differ with regions, species, and altitude because the temperature required for each organism to grow and develop varies and accumulates differently according to region. This is the earliest degree-day summation concept, and for hundreds of years, this concept has been a fundamental basis for constructing bioclimatic models, such as the spring index model (Schwartz 1997; Schwartz and Marotz 1986, 1988), thermal time model (Cannell and Smith 1983; Robertson 1968), and spring warming model (Hunter and Lechowicz 1992).

After Reaumur, three types of bioclimatic models were developed in response to different research needs, methods, and objectives. Scientists refer to the three model types as theoretical, statistical, and mechanistic models. The theoretical model is also called the analytical model because it emphasizes the equilibrium between the productivity and the energy and nutrition absorption of leaves. Thus, because the model focuses on growth and development, it is suitable for research regarding the evolution of the survival strategies of species. The statistical model encompasses a wide and complex research scope. The primary objective of this model is to conduct statistical modeling, such as polynomial regression and general linear models, based on bioclimatic observation to directly connect climatic factors and biological events. Therefore, this model is also referred to as the empirical model. The mechanistic model focuses on the causal relationship between bioclimatic events and environmental factors to explain the effects of environmental factors on plant physiology. Because rigorous physiological and ecological theories and experimental bases support this model, its results are accepted relatively easily by a majority of scholars. The mechanistic model has been the standard of bioclimatic model research for a long period (Zhao et al. 2013). Except for the few bioclimatic models that use simple calculations, difficulties have typically been encountered during the early development of other bioclimatic models. These models were not developed and widely used until computer software and hardware became more easily accessible and a concomitant increase in the availability of data to parameterize such models (e.g., freely available gridded climate products) resulted in a stronger emphasis on global climate changes.

Each bioclimatic model has specific application restrictions and advantages and disadvantages. Scientists use the thermal time model most often because this model considers only the accumulated temperature, threshold temperature, and mean daily temperature of bioclimatic events as the parameters, facilitating model application. The model is shown as follows:

$$
S_{f}=\sum_{t_{0}}^{y} R_{f}\left(X_{t}\right)=F^{*}
$$

where $S_{f}$ represents the accumulated units required to promote growth that satisfies bioclimatic event occurrence; $y$ represents the date of the bioclimatic event occurrence; $t_{0}$ represents the initial time for calculating the accumulated temperature; $X_{t}$ represents the mean daily temperature; and $R_{f}\left(X_{t}\right)$ represents the calculation function of effective accumulated temperature. This function is calculated using the following equation:

$$
R_{f}\left(X_{t}\right)= \begin{cases}0 & \text { if } x_{t} \leq T_{b 1} \\ x_{t}-T_{b 1} & \text { if } x>T_{b 1}\end{cases}
$$


where $T_{b 1}$ represents the initial temperature for calculating the accumulated temperature. In this model, when the temperature is below the threshold growth temperature of a plant, the temperature does not influence phenological events. Only when the temperature exceeds the threshold growth temperature of a plant does the accumulated temperature affect phenological events. The higher the temperature, the greater the degree of influence is. However, this model is only applicable to the optimal temperature of plant growth. When the plant encounters extreme temperatures that exceed the optimal temperature of growth during the calculation of plant-accumulated temperature, the prediction errors of the model increase. Thus, several scientists have established the following formula to calculate the effective accumulated temperature based on the curves of plant growth development in response to temperatures.

$$
R_{f}\left(x_{t}\right)= \begin{cases}0 & \text { if } x_{t}<0 \\ \frac{a}{1+e^{b\left(x_{t}-c\right)}} & \text { if } x_{t} \geq 0\end{cases}
$$

where $\mathrm{c}$ represents the optimal temperature for plant growth, b represents the parameter of plant sensitivity to variations in effective accumulated temperature, and a represents the upper limit of effective accumulated temperatures when bioclimatic events occur. This formula categorizes temperatures below $0{ }^{\circ} \mathrm{C}$ as noninfluential on bioclimatic events and involves only temperature accumulation above $0{ }^{\circ} \mathrm{C}$.

The review of previous models shows that early thermal time models considered only the forcing units of growth, rather than the chilling requirements. In addition, during dormancy, plants are completely quiescent; thus, the phenological phase during dormancy is difficult to observe and define. However, a high number of physiological experiments in later stages have shown that low temperatures are necessary in winter for temperate plants to blossom and sprout. Bioclimatic models that neglect chilling requirements cannot effectively predict the flowering and sprouting of temperate plants. Therefore, scientists have developed numerous mechanistic models based on differing physiological plant types and have integrated chilling requirements into various models. Among these models, the most well-known are the sequential model (Hänninen 1987, 1990; Sanders 1975; Sarvas 1974), parallel model (Landsberg 1974; Sarvas 1974), alternating model (Cannell and Smith 1983; Kramer 1994; Murray et al. 1989), deepening rest model (Kobayashi et al. 1982), and four phase model (Hänninen 1990; Vegis 1964).

The differences between these bioclimatic models are as follows: The sequential model emphasizes that forcing temperature is effective only after chilling requirements are met, presenting a sequential order. Landsberg (1974) proposed the parallel model for identifying the dormancy characteristics of apple buds, indicating that regardless of temperatures, the phenological expression of plants is affected. The alternating model emphasizes that the forcing units and chilling units possess a negative indicative correlation. Thus, the two requirements alternatively influence phenological expression based on different weighting degrees with variations in the dormancy stages of plants. Kobayashi et al. (1982) proposed the deepening rest model in their study regarding the bud dormancy characteristics of Cornus sericea L. This model emphasizes that chilling requirements occur only during the deep rest stage, and that calculations of chilling requirements are not necessary for other dormancy stages. The four phase model emphasizes that plants have four sub-phenological phases during dormancy, which are the prerest, true-rest, postrest, and quiescence phases. The critical temperature-forced growth increases continuously during the prerest phase, but decreases during the postrest phase. In the true-rest phase, plants do not respond to any forcing growth temperature. The critical plant growth temperature decreases to the lower limit of initial temperatures for plant development in the postrest phase. When the external temperature remains below the lower limit temperature, plants enter the quiescence phase, the length of which is determined by the physiological conditions of the plant and the temperature increase in the following spring.

Regarding the measurement of the chilling requirements of plants in thermal time models, two common calculation methods exist:

$$
R_{c}\left(x_{t}\right)= \begin{cases}1 & \text { if } x_{t}<T_{b 2} \\ 0 & \text { if } x_{t} \geq T_{b 2}\end{cases}
$$

where $R_{f}$ becomes $R_{c}$, indicating that the growth accumulated temperature is replaced by the accumulated low temperature of chilling requirements, and $T_{b 2}$ represents the upper limit of the critical temperature of effective low temperatures. Temperatures higher than $T_{b 2}$ have no effect on the temperature accumulation of chilling requirements. Only temperatures lower than $T_{b 2}$ affect the temperature accumulation of plant chilling requirements. Binary coding is adopted to calculate the effective accumulated temperature. In other words, regardless of temperature values lower than the critical temperature, one effective chilling unit is counted. Even if the temperature is $-50{ }^{\circ} \mathrm{C}$, which freezes plants to death, an effective chilling unit is counted. This formula obviously contradicts empirical experience. Therefore, subsequent scientists have developed another formula for calculating the effective chilling unit:

$$
R_{c}\left(x_{t}\right)= \begin{cases}0 & \text { if } x_{t} \leq T_{m} \text { or } x_{t} \geq T_{M} \\ \frac{x_{t}-T_{m}}{T_{0}-T_{m}} & \text { if } T_{0}>x_{t}>T_{m} \\ \frac{x_{t}-T_{M}}{T_{0}-T_{M}} & \text { if } T_{0}<x_{t}<T_{M}\end{cases}
$$


where $T_{m}$ and $T_{M}$ represent the upper and lower limits of the effective low temperatures of plants, respectively. When the external temperature is lower or higher than the upper and lower limits, the accumulated temperatures for plant chilling requirements are not effective. The term $T_{0}$ refers to the most effective chilling requirement temperature of plants. Clearly, this formula meets the actual situation more accurately than formula (4) does.

Different plant bioclimatic models combined with various plant physiological types must be calculated using different methods. For example, when thermal time models are used to predict plant flowering on the sequential model, the plant chilling requirements must be calculated and satisfied before the growth-accumulated temperature of plants is calculated. If parallel models are used, chilling accumulated temperature and forcing accumulated temperature must also be calculated to predict bioclimatic events. Hence, dozens of model combinations for predicting plant flowering or sprouting by using the thermal time model are available. The high degree of plant bioclimatic and physiological diversity contributes to the complex development of bioclimatic models. The complexity of bioclimatic model development, to a certain degree, effectively increases the accuracy of bioclimatic prediction; however, such complexity also impedes the promotion and application of the models. To simplify the application of bioclimatic models, Chuine (2000) combined numerous major mechanistic models and developed a set of unified bioclimatic model calculation methods, which comprises two formulas to calculate the forcing and chilling requirements of plants. Through the adjustment of various parameters in the model, Chuine fitted the plant differences resulting from physiological responses, phenological phases, regions, and latitudes. Subsequently, Chuine and Beaubien (2001) further argued that the distribution of woody plants is primarily determined by the degree of fitness of the plant bioclimatology to the local climates. Thus, they integrated other models, such as those of freeze injury and fruit ripening, to develop a bioclimatic model based on biological processes, which they referred to as the PHENOFIT model. The model uses bioclimatic observation data for parameter fitting of bioclimatic models and meteorological variable map layers provided by Environment Canada, Climate Archives, the National Climatic Data Center, and the World Radiation Center to determine species distribution according to the fitting degree of the species bioclimatology to the local climates. Because the PHENOFIT model combines multiple bioclimatic models, the calculation formula is complex. Nevertheless, the PHENOFIT model requires the input of only five variables to obtain 12 variables that explain the effects of climates on species. These resulting variables altogether can determine the distribution appropriateness of species. The PHENOFIT model uses climatic data from various geographic regions to infer the distribution of numerous temperate perennial woody plants. The results indicated that the outcomes inferred using the model highly corresponded to the actual distribution of the target species.

The temperature, light, water availability, and airflow changes caused by climate changes influence the transpiration rate of leaves, which is determined by numerous factors, such as the net radiation balance of leaves, water supply conditions, leaf shapes, environmental wind speed, and the reaction of the stomata to transpiration sensitivity (Gates 1968; Raschke 1960). The model is as follows:

$$
\begin{aligned}
& S_{t}\left(1-\alpha_{l}\right)+L_{d}-\varepsilon \sigma T_{a}^{4} \\
& \quad=\frac{\rho C_{p}\left(T_{l}-T_{a}\right)}{r_{a}}+\frac{\rho C_{p}}{\gamma^{*}} \frac{\left(e_{o}-e_{a}\right)}{r_{s}+r_{a}}
\end{aligned}
$$

where $S_{t}$ represents the incoming solar radiation $\left(\mathrm{Wm}^{-2}\right) ; \alpha_{l}$ is the albedo of the leaf; $L_{d}$ is the incoming longwave radiation $\left(\mathrm{Wm}^{-2}\right) ; \varepsilon \sigma T^{4}$ is the long-wave radiation emitted by the leaf at the leaf temperature $\left(T_{l}\right) ; \rho$ is the environmental air density around the leaf $\left(\mathrm{kgm}^{-3}\right) ; C_{p}$ is the specific heat of air $(\mathrm{kPa}) ; T_{a}$ is the air temperature $\left({ }^{\circ} \mathrm{C}\right) ; r_{a}$ is the aerodynamic conductance to heat transfer $\left(\mathrm{sm}^{-1}\right) ; \gamma^{*}$ is the psychrometric constant $\left(\mathrm{kPa}{ }^{\circ} \mathrm{C}^{-1}\right) ; e_{0}$ is the saturated vapor pressure $(\mathrm{kPa})$ at the current leaf temperature; $e_{a}$ is the actual vapor pressure $(\mathrm{kPa})$; and $r_{s}$ represents the stomatal conductance $\left(\mathrm{sm}^{-1}\right)$. Formula (6) shows that a slight change in the temperature affects multiple factors simultaneously. When the air temperature increases, the long-wave radiation absorption of leaves is affected, increasing the thermal load of leaves and changing the saturated vapor pressure in the atmosphere. Consequently, the actual vapor pressure is insufficient and causes the water transpiration rate of the leaf to increase along with water consumption. Thus, the model can effectively evaluate the effects of temperature, light, water availability, and airflow changes on plants according to climate changes. Moreover, stomatal conductance differs with the sensitivity of plant species and strains to climate changes (Hofstra and Hesketh 1969).

Because of article length limitations, we introduced only three major types of plant bioclimatic models. In addition to the models introduced in this study, other bioclimatic models are of importance in separate fields of development. Basically, the diversity of relationships between organisms and climates leads to diversity among statistical (empirical) models, such as the thermal time, degree-days, heat sums, growing degree-days, physiological time, and spring warming models. The 
physiological and genetic diversity of organisms contributes to the diversity of mechanistic models, such as the parallel, sequential, deepening rest, four phases, Utah (Richardson et al. 1974), positive chill (Linsley-Noakes et al. 1995), and North Carolina models (Gilreath and Buchanan 1981). The diversity of biological and statistical theories contributes to the diversity of theoretical models, such as the models based on carbon equilibrium, the interaction of hormones, survival and reproductive adaptation, ecological niches, genetic behaviors, biological processes, and remote sensing. Naturally, some of the models involve a certain degree of correlation, which occasionally enables their mutual and complementary combination.

By reviewing the development of early bioclimatic models, we identified the following tendencies: (a) The number of studies regarding the bioclimatic models for perennial species substantially exceeds that of those for annual plants. (b) The number of bioclimatic model studies on temperate plants is considerably higher than that of those on tropical and subtropical plants. (c) The number of bioclimatic model studies on woody plants is substantially higher than that of those on herbal plants. (d) The number of observational bioclimatic model studies is substantially higher than that of experimental studies. (e) The number of bioclimatic model studies on plants that sprout and blossom in spring is considerably higher than that of those on plants with different growth and development stages. (f) The number of bioclimatic model studies on crops greatly exceeds that of those on forest plants. The majority of the bioclimatic model research conducted after 1753 has focused on the flowering and sprouting models of temperate plants. Regarding other bioclimatic models, only a few model studies on fruit ripening bioclimatology were found (Piper et al. 1996; Song and $\mathrm{Ou}$ 1997). Moreover, research on the bioclimatic model of leaf colouring periods is scant (Chuine and Beaubien 2001).

\section{Application of plant bioclimatic models in evaluating the influence of climate changes}

Plant bioclimatic models have been applied and developed in different fields, such as for predicting and evaluating the influence of climate changes on plant bioclimatology (Hänninen and Tanino 2011; Hänninen et al. 2007; Hao et al. 2001; Morin et al. 2009), improving the primary productivity of ecosystem (Kramer and Mohren 1996; Watsona et al. 2013), helping patients with pollinosis predict the time when pollen will occur in the air (Frenguelli and Bricchi 1998), assisting in crop or forest management and disaster-risk decision assessment, diagnosing the effects of climate on crop growth and development, predicting or assessing the correlations between species and their survival or adaptive strategy evolution (Chuine and Beaubien 2001; Morin et al. 2008), rebuilding regional climate environments in the past (Maurer et al. 2011; Menzel 2005; Yiou et al. 2012), forecasting the flowering time of cherry blossoms for developing the tourisy industry (Allen et al. 2014), and diagnosing the growth and development conditions of organisms as well as diseases and pests (Villalta et al. 2007). Unsurprisingly, these applications are correlated with one other to a certain degree. In recent years, plant bioclimatic models have been continuously applied to climate change research to evaluate the effects of climate changes on organisms. This implies that the importance of applying plant models in climate change-related research has constantly increased (Peñuelas and Filella 2001). Thus, this study introduced the application of bioclimatic models in assessing the influence of climate changes and in disaster prevention.

Initially, scientists focused on how plant sprouting and leaf expansion in the spring are correlated with freeze and cold injuries in the spring. Thus, statistical and mechanistic models regarding plant sprouting were the first models used to evaluate the effects of climate changes on plants. These models are often used to evaluate plants' ability to resist freezing or frost injuries (Cannell 1985; Cannell and Smith 1986; Hänninen 1991) or the competition for light that occurs among different species after climate changes (Cesaraccio et al. 2004). As bioclimatic model research progresses, theoretical models such as the DORMPHOT model, which is based on theoretical processes, are frequently used to assess the effects and risks of extremely low temperatures and freezing and cold injuries on forests. Theoretical models are also used to assess the risks of native species being affected by climate changes (Kramer 1995; Kramer et al. 1996; O'Neill et al. 2010). Based on an empirical experiment, the DORMPHOT model was more accurate than traditional models in assessing tree sprouting (Caffarra et al. 2011; Zottele et al. 2011).

Regarding the assessment of the effects of climate changes on plant bioclimatology, productivity, vegetation structures, vegetation dynamics, and forest landscapes, forest gap models that contain climate variables are often used to explain the effects of climate changes on forest succession, growth, landscapes, and the structural variations of plant communities (Bugmann 2001; Keane et al. 2001; Prentice et al. 1993). Additionally, because of the differing sensitivities of the models, the response degree of forest primary productivity models varies with the model adopted (Leinonen and Kramer 2002; Vitasse et al. 2011). Common instances are the effects of energy and carbon dioxide flows on leaf expansion and falling leaf bioclimatology, and the model for assessing the 
relationship between leaf area index and seasonal evolution (Chase et al. 1996). In addition, empirical (statistical) degree-day growing models are frequently used in investigating the bioclimatic changes and carbon sequestration cycles in land surface models (Arora and Boer 2005; Baldocchi et al. 2005; Delpierre et al. 2009; Vitasse et al. 2011). Similarly, regarding the effects of climate changes on the carbon sequestration ability of vegetation, the large-scale biological sphere model based on forest ecological system processes, BIOME-BGC, includes information on leaf growth and falling dates as parameters and applies the information to three types of vegetation research (Running and Hunt 1993).

The prediction results of bioclimatic modeling or the models themselves can be integrated with other models with various purposes to conduct research on the effects of climate changes (Halofsky et al. 2013). For example, Bonan (1998) used the monthly leaf area indices predicted using the land surface model of the National Center for Atmospheric Research as model parameters and applied the parameters to the grids of the Community Climate Model to facilitate global climate change research. Kaduk and Heimann (1996) determined the precautionary and mechanical structures that identify bioclimatology phases in environmental conditions and applied the structure to land carbon cyclic model research. Botta et al. (2000) used remote sensing data to estimate leaf sprouting time and developed empirical prediction formulas to predict leaf bioclimatology dynamics and propose a global bioclimatology precautionary structure. In addition, other professional bioclimatic models of climate change for large-scale structures based on biospheres or ecological systems exist, such as the Frankfurt biosphere model established based on the carbon equilibrium structure; the Lund-Potsdam-Jena dynamic global vegetation model, which assesses ecological system dynamics, plant geography, and land field carbon cycles (Sitch et al. 2003); the Canadian Centre for Climate Modeling and Analysis integrated biosphere simulator model, which predicts leaf bioclimatology based on light and temperature functions (Foley et al. 1996); and the forest carbon model based on photosynthesis and transpiration (Chiang and Brown 2007). These models have been widely applied in large-scale climate change research in recent years.

Recently, ecologists have focused on the effects of climate changes on species distribution, the resulting habitat fragmentation, and relevant species conservation arguments (Channell and Lomolino 2000; Crimmins et al. 2013; Fan et al. 2013; Gavin et al. 2014; Pauli et al. 2014; Pimm et al. 2014; Renton et al. 2013). Thus, numerous species distribution models developed on the based of the climate ecological niche theory of bioclimatic models have been applied in research on the effects of climate changes on species distribution and habitats. A major portion of these models are also referred to as climate envelope models (CEMs) (Hijmans and Graham 2006), such as the maximum entropy models (Phillips et al. 2004), machine-learning-based artificial neural network models, and integrated species distribution models (e.g., BIOMOD) (Coetzee et al. 2009; Thuiller 2003). However, not all species distribution models are categorized as CEMs. For example, although the PHENOFIT model was developed on the basis of biological processes and many physiologically based SDMs (Kearney and Porter 2009) are used to evaluate the effects of climate changes on species distribution, they are not CEMs.

The mapped atmosphere-plant-soil system model (Lenihan et al. 2003, 2008) can be used to assess the effects of climate changes on vegetation distribution, ecological system productivity, or forest fires. Remotesensing time sequential data can be used to measure and assess land field surface phenology for assessing the vegetation responses after fires (van Leeuwen et al. 2010). In addition, regarding large-scale biological effect research, the BIOME-BGC, CLASS, Interannual Flux Tower Upscaling Sensitivity Experiment, third generation Coupled Global Climate Model, I/O buffer information specification, Lund-Potsdam-Jena, National Center for Atmospheric Research Land Surface Model, and remote-sensing-based NDVI/NDWI models can be used for assessing the effects of climate changes on large areas of vegetation (Bonan 1998; Desai 2010; Foley et al. 1996; Sitch et al. 2003). These models are convenient for use in large plain areas; thus, they have been widely adopted by studies in numerous temperate continental countries in recent years.

The types, application methods, and purposes of bioclimatic models are numerous, and the predictive accuracy of the models is determined by (a) the quality and quantity of data, (b) whether the user selects and uses the most appropriate model, and (c) the accuracy in forecasting climate changes. Because scientists mostly focus on (a) and (b), this paper does not discuss item (c), which requires the expertise of meteorologists. In particular, the situation described in (a) is inevitable when any model is used. However, because various models require different levels of data sensitivity, the requirements for data quality and quantity also differ. The requirements for data quality and accuracy are strict and are often based on bioclimatic models driven by data, such as the maximum entropy model, CEMs, and machine-learning models used for species distribution modeling. Thus, the preparation and compilation works of data are critical in these types of model. Two conditions are used to determine whether a user has selected and used the appropriate model. The 
first condition is the user's understanding of the target organisms' physiology, ecology, behavior, or biology. For example, if the constrain conditions of the distribution of a species is not a climatic factor, using CEMs and current species distribution data to assess the effects of climate changes on species distribution may lead to considerable errors. Therefore, to use bioclimatic models to assess the effects of climate changes on organisms, is necessary to identify the period in the target organisms' life cycle that is most sensitive to climate changes. Subsequently, based on the period, a suitable model should be selected for conducing assessment to maximize the effectiveness of the model. Choosing an inappropriate model to conduct assessment typically results in errors (Coetzee et al. 2009).

All applications of bioclimatic models in assessing the effects of climate changes have advantages and disadvantages (Elith et al. 2006; Hijmans and Graham 2006). For example, statistical models are the most widely used and are user-friendly and users are not required to consider biological processes, genetics, and physiology; however, they lack explanatory power for the research results and have a limited scopes of applications. Statistical models generally can not be applied to research on the effects on large areas of vegetation variations. Mechanistic models yield the highest explanatory power for the effects of climate changes, and thus have optimal assessment effectiveness. However, uncertainty of species' physiological mechanisms is a constraining factor of using such models. For instance, users may be uncertain regarding what model to use to assess the effects of climate changes on the dormancy of Sassafras randaiense Hay. Rehder because the bud dormancy and physiology of the plant species have not yet been thoroughly investigated. Regarding the research on bioclimatic models for exploring the effects of climate changes, the successful application of models is determined by the user's understanding of each model. Only by selecting suitable models can reliable assessment on the effects of climate changes be conducted and accurate results be attained.

In our previous review of climate change research on plants (Hsieh and Chiou 2013), we found that phenological gardens and phenological observation networks are used to record the effects of past climate changes on organisms in climate change research and monitor the direct influence of climate changes on organisms. Bioclimatic models are used to assess the possible effects of future climate changes and assist in making disasterprevention decisions. Bioclimatic models and phenological observation networks are complementary in assessing the effects of climate changes; neither can be neglected. Without the historical records of phenological observation networks, bioclimatic models lack modeling data; without bioclimatic models, phenological observation networks lack the function of risk assessment and cannot assist in disaster-prevention decision-making. Thus, phenological fingerprints and models have been developed rapidly for applications in international climate change research. The use of regional phenological fingerprints, which was once a tool for small- to medium-scale spaces, has been expanded to continental and global scales through the establishment of global bioclimatic monitoring plans (Bruns et al. 2003; Parmesan and Yohe 2003; Root et al. 2003). Regarding the application of models, although the global bioclimatic models developed on the basis of remote sensing data have been widely applied in studies in temperate continental countries in Europe and North America, small- to medium-scale phenological fingerprints and models are more suitable for Taiwan because of its small terrain.

\section{Conclusion}

The effects of global climate changes have increased in recent years. Numerous cities in Europe, the United States, China, and Japan were measured to have had high temperatures exceeding $40{ }^{\circ} \mathrm{C}$ for several consecutive days throughout the summer of 2013. Torrential rain has caused disasters in numerous regions and weather stations all over the planet measured atmospheric carbon dioxide concentrations exceeding $400 \mathrm{ppm}$, the highest in millions of years. Moreover, climate changes have exerted increasingly severe effects on plants and wildlife (Anderegg et al. 2012; Harley 2011; Ibáñez et al. 2008; Inouye 2008; Kaschner et al. 2011; Moritz et al. 2008; Rode et al. 2010; van Mantgem et al. 2009). These disasters indicate that the threats of climate change are ubiquitous. Because of the global impacts of disasters, we suggest that all countries' government and relevant research units immediately establish international phenology gardens and network systems, develop phenological fingerprint observation technologies, improve the ability to monitor the effects of climate changes on global organisms, and employ long-term bioclimatic observation records to develop bioclimatic models that are suitable for local climates and disaster prevention. Consequently, the capacity for assessing the effects of climate changes and predicting and preventing disasters can be prepared, and measures and strategies can be prepared in response to disasters caused by climate changes.

\section{Authors' contribution}

CRC conceived and designed the topics. TYH collecting literature and wrote the paper. CCC edited the manuscript. All authors read and approved the final manuscript.

\section{Author details}

${ }^{1}$ School of Forestry and Resource Conservation, National Taiwan University, No. 1, Sec. 4, Roosevelt Rd., Taipei 10617, Taiwan (R.O.C.). ${ }^{2}$ Shanghai Institutes for Biological Sciences, Chinese Academy of Sciences, 320 Yue Yang Rd., Shanghai 200031, China. ${ }^{3}$ Shanghai Chenshan Plant Science Research Center, 
Chinese Academy of Sciences, 3888 Chenhua Road, Songjiang, Shanghai 201602, China. ${ }^{4}$ Shanghai Key Laboratory of Plant Functional Genomics and Resources, Shanghai Chenshan Botanical Garden, 3888 Chenhua Road, Songjiang, Shanghai 201602, China. ${ }^{5}$ College of Business, Chung Yuan Christian University, 200, Chung Pei Rd., Chung Li 32023, Taiwan (R.O.C.).

\section{Acknowledgements}

We thank two anonymous reviewers for their comments and suggestions. This study was supported by the Chinese Academy of Sciences (Grant no.: 2013 TW2SA 0003, 2015TW1SA0001), the Forestry Bureau, Council of Agriculture, Executive Yuan (Grant no.: 101 agriculture-13.5.4-forestry-e1) and the National Science Council (Grant no.: NSC 102-2313-B-002-038).

\section{Compliance with ethical guidelines}

\section{Competing interests}

The authors declare that they have no competing interests

Received: 19 March 2015 Accepted: 26 August 2015

Published online: 21 September 2015

\section{References}

Allen JM, Terres MA, Katsuki T, Iwamoto K, Kobori H, Higuchi H, Primack RB, Wilson AM, Gelfand A, Silander JA Jr (2014) Modeling daily flowering probabilities: expected impact of climate change on Japanese cherry phenology. Glob Change Biol 20:1251-1263

Anderegg WR, Berry JA, Smith DD, Sperry JS, Anderegg LD, Field CB (2012) The roles of hydraulic and carbon stress in a widespread climate-induced forest die-off. Proc Natl Acad Sci 109:233-237

Arora VK, Boer GJ (2005) A parameterization of leaf phenology for the terrestrial ecosystem component of climate models. Glob Chang Biol 11:39-59

Baldocchi DD, Black T, Curtis P, Falge E, Fuentes J, Granier A, Gu L, Knohl A, Pilegaard K, Schmid H (2005) Predicting the onset of net carbon uptake by deciduous forests with soil temperature and climate data: a synthesis of FLUXNET data. Int J Biometeorol 49:377-387

Bawa KS, Hadley M (1991) Reproductive ecology of tropical forest plants. CRC Pres, Paris, p 422

Bonan GB (1998) The land surface climatology of the NCAR land surface model coupled to the NCAR community climate model. J. Climate 11:1307-1326

Botta A, Viovy N, Ciais P, Friedlingstein P, Monfray P (2000) A global prognostic scheme of leaf onset using satellite data. Glob Chang Biol 6:709-725

Bruns E, Chmielewski FM, VanVliet AJH (2003) The global phenological monitoring concept. Phenology 39:93-104

Bugmann H (2001) A review of forest gap models. Clim Change 51:259-305

Caffarra A, Donnelly A, Chuine I (2011) Modelling the timing of Betula pubescens budburst. II. Integrating complex effects of photoperiod into process-based models. Clim Res. 46:159-170

Campbell RK, Sugano Al (1975) Phenology of bud burst in Douglas-fir related to provenance, photoperiod, chilling, and flushing temperature. Bot Gaz 36:290-298

Campbell-Clause JM (1998) Stomatal response of grapevines to wind. Aust J Exp Agric 38:77-82

Cannell MGR (1985) Analysis of risks of frost damage to forest trees in Britain. Helsinki University Press, Helsinki, pp 153-166

Cannell MGR, Smith RI (1983) Thermal time, chill days and prediction of budburst in Picea sitchensis. J Appl Ecol 20:951-963

Cannell MGR, Smith RI (1986) Climatic warming, spring budburst and forest damage on trees. J Appl Ecol 23:177-191

Cannell MGR, Murray MB, Sheppard LJ (1985) Frost avoidance by selection for late budburst in Picea sitchensis. J Appl Ecol 22:931-941

Cesaraccio C, Spano D, Snyder RL, Duce P (2004) Chilling and forcing model to predict bud-burst of crop and forest species. Agr Forest Meteorol 126:1-13

Channell R, Lomolino MV (2000) Dynamic biogeography and conservation of endangered species. Nature 403:84-86

Chase TN, Pielke RA, Kittel TG, Nemani R, Running SW (1996) Sensitivity of a general circulation model to global changes in leaf area index. J Geophys Res 101:7393-7408
Chiang JM, Brown KJ (2007) Improving the budburst phenology subroutine in the forest carbon model PnET. Ecol Model 205:515-526

Chien CT, Yang JJ, Chung YL, Lin TP (1995) Germination promotion of taxus mairei seed by combination of warm and cold stratification. Bull Taiwan For Res Inst 10:331-336

Chu KC, Wan MW (1999) Phenology. Hunan Education Publishing House, Changsha, p 173

Chuine I (2000) A unified model for budburst of trees. J Theor Biol 207:337-347

Chuine I, Beaubien EG (2001) Phenology is a major determinant of tree species range. Ecol Lett 4:500-510

Coetzee BW, Robertson MP, Erasmus BF, Van Rensburg BJ, Thuiller W (2009) Ensemble models predict Important Bird Areas in southern Africa will become less effective for conserving endemic birds under climate change. Glob Ecol Biogeogr 18:701-710

Crimmins SM, Dobrowski SZ, Mynsberge AR (2013) Evaluating ensemble forecasts of plant species distributions under climate change. Ecol Model 266:126-130

Darnell RL, Hancock JF (1996) Balancing vegetative and reproductive growth in strawberry. In: Pritts CKC, Crocker TE (eds) Proceedings of the IV North American Strawberry Conference, pp 144-150

de Lampe MG, Bergeron Y, McNeil R, Leduc A (1992) Seasonal flowering and fruiting patterns in tropical semi-arid vegetation of northeastern Venezuela. Biotropica 24:64-76

Delpierre N, Soudani K, Francois C, Köstner B, Pontailler JY, Nikinmaa E, Misson L, Aubinet M, Bernhofer C, Granier A (2009) Exceptional carbon uptake in European forests during the warm spring of 2007: a data-model analysis. Glob Change Biol 15:1455-1474

Desai AR (2010) Climatic and phenological controls on coherent regional interannual variability of carbon dioxide flux in a heterogeneous landscape. J Geophys Res 115:G00J02

Duryea ML, Blakeslee GM, Hubbard WG, Vasquez RA (1996) Wind and trees: a survey of homeowners after Hurricane Andrew. J Arboric 22:44-50

Elith J, Graham CH, Anderson RP, Dudík M, Ferrier S, Guisan A, Hijmans RJ, Huettmann F, Leathwick JR, Lehmann A, Li J, Lohmann LG (2006) Novel methods improve prediction of species' distributions from occurrence data. Ecography 29:129-151

Fan YH, Nee CC (2007) Dormant character of different Actinidia callosa groups native in Taiwan. Seed Nurs (Taiwan) 9:49-62

Fan J, Li J, Xia R, Hu L, Wu X, Li G (2013) Assessing the impact of climate change on the habitat distribution of the giant panda in the Qinling Mountains of China. Ecol Model 274:12-20

Foley JA, Prentice IC, Ramankutty N, Levis S, Pollard D, Sitch S, Haxeltine A (1996) An integrated biosphere model of land surface processes, terrestrial carbon balance, and vegetation dynamics. Glob Biogeochem Cy 10:603-628

Frenguelli G, Bricchi E (1998) The use of the pheno-climatic model for forecasting the pollination of some arboreal taxa. Aerobiologia 14:39-44

Fuchigami LH, Weiser CJ, Kobayashi K, Timmis R, Gusta LV (1982) A degree growth stage (GS) model and cold acclimation in temperate woody plants. In: Li PH, Sakai A (eds) Plant cold hardiness and freezing stress. Academic Press, New York, pp 93-116

Gates DM (1968) Transpiration and leaf temperature. Annu Rev Plant Phys 19:211-238

Gavin DG, Fitzpatrick MC, Gugger PF, Heath KD, Rodríguez-Sánchez F, Dobrowski SZ, Hampe A, Hu FS, Ashcroft MB, Bartlein PJ, Blois JL, Carstens BC, Davis EB, Lafontaine G, Edwards ME, Fernandez M, Henne PD, Herring EM, Holden ZA, Kong W, Liu J, Magri D, Matzke NJ, McGlone MS, Saltre F, Stigall AL, Tsai YHE, Williams JW (2014) Climate refugia: joint inference from fossil records, species distribution models and phylogeography. New Phytol 204:37-54

Gilreath P, Buchanan D (1981) Rest prediction [mathematical] model for lowchilling 'Sungold' nectarine. J Am Soc Hortic Sci 106:426-429

Haldane JBS (1947) Science advances, 1st edn. Macmillan, London, p 252

Halofsky JE, Hemstrom MA, Conklin DR, Halofsky JS, Kerns BK, Bachelet D (2013) Assessing potential climate change effects on vegetation using a linked model approach. Ecol Model 266:131-143

Hänninen H (1987) Effects of temperature on dormancy release in woody plants: implications of prevailing models. Silva Fenn 21:279-299

Hänninen H (1990) Modelling bud dormancy release in trees from cool and temperate regions. Finnish Forest Research Institute, Finland, p 47 
Hänninen H (1991) Does climatic warming increase the risk of frost damage in northern trees? Plant, Cell Environ 14:449-454

Hänninen H, Tanino K (2011) Tree seasonality in a warming climate. Trends Plant Sci 16:412-416

Hänninen H, Slaney M, Linder S (2007) Dormancy release of Norway spruce under climatic warming: testing ecophysiological models of bud burst with a whole-tree chamber experiment. Tree Physiol 27:291-300

Hao ZQ, Dai LM, He HS, Malandnoff DJ, Shao GF (2001) Potential response of major tree species to climate warming in Changbai Mountain, Northeast China. Chin J Appl Ecol 12:653-658

Harley CD (2011) Climate change, keystone predation, and biodiversity loss. Science 334:1124-1127

Heide OM (1974) Growth and dormancy in Norway spruce ecotypes. Physiol Plantarum 31:131-139

Heide OM (1993) Daylength and thermal time responses of budburst during dormancy release in some northern deciduous trees. Physiol Plantarum 88:531-540

Hijmans RJ, Graham CH (2006) The ability of climate envelope models to predict the effect of climate change on species distributions. Glob Chang Biol 12:2272-2281

Hofstra G, Hesketh JD (1969) The effect of temperature on stomatal aperture in different species. Can J Bot 47:1307-1310

Hopkins AD (1938) Bioclimatics: a science of life and climate relations. United States Department of Agriculture, Washington, DC, p 188

Hsieh TY, Chiou CR (2013) Phytophenology and its applications in climate change research: review and future perspectives. Q J Chin For 46:391-410

Hsieh TY, Nee CC, Chien CT (2004) Seed germination of Taiwanese Actinidia latifolia (Gardn. and Champ.) Merr. Taiwan J For Sci 19:173-176

Huang YW (2011) Establishment of cherry blossoming model in Taiwan. Department of Forestry and Resource Conservation, National Taiwan University, Taipei, p 95

Hunter AF, Lechowicz MJ (1992) Predicting the timing of budburst in temperate trees. J Appl Ecol 29:597-604

Ibáñez I, Clark JS, Dietze MC (2008) Evaluating the sources of potential migrant species: implications under climate change. Ecol Appl 18:1664-1678

Inouye DW (2008) Effects of climate change on phenology, frost damage, and floral abundance of montane wildflowers. Ecology 89:353-362

Isikawa S (1954) Light-sensitivity against the germination. I." Photoperiodism" of seeds. Bot Mag (Tokyo) 67:51-56

Johnson LRC, Irgens-Moller H (1964) Effect of photoperiod and light quality on germination of douglas-fir seed. Forest Sci. 10:200-205

Kaduk J, Heimann M (1996) A prognostic phenology scheme for global terrestrial carbon cycle models. Clim Res 6:1-19

Kaschner K, Tittensor DP, Ready J, Gerrodette T, Worm B (2011) Current and future patterns of global marine mammal biodiversity. PLoS One 6:e19653

Keane RE, Austin M, Field C, Huth A, Lexer MJ, Peters D, Solomon A, Wyckoff $P$ (2001) Tree mortality in gap models: application to climate change. Clim Change 51:509-540

Kearney M, Porter W (2009) Mechanistic niche modelling: combining physiological and spatial data to predict species'ranges. Ecol Lett 12:334-350

Kellomäki S, Hänninen H, Kolström M (1995) Computations on frost damage to Scots pine under climatic warming in boreal conditions. Ecol Appl $5: 42-52$

Kobayashi KD, Fuchigami LH, English MJ (1982) Modeling temperature requirements for rest development in Cornus sericea. J Am Soc Hortic Sci 107:914-918

Körner C, Basler D (2010) Phenology under global warming. Science 327:1461-1462

Kramer K (1994) Selecting a model to predict the onset of growth of Fagus sylvatica. J Appl Ecol 172-181

Kramer K (1995) Modelling comparison to evaluate the importance of phenology for the effects of climate change on growth of temperate-zone deciduous trees. Clim Res 5:119-130

Kramer K, Mohren GMJ (1996) Sensitivity of FORGRO to climatic change scenarios: a case study on Betula pubescens, Fagus sylvatica and Quercus robur in the Netherlands. Clim Change 34:231-237

Kramer K, Friend A, Leinonen I (1996) Modelling comparison to evaluate the importance of phenology and spring frost damage for the effects of climate change on growth of mixed temperate-zone deciduous forests. Climate Res 7:31-41
Landsberg JJ (1974) Apple fruit bud development and growth; analysis and an empirical model. Ann Bot 38:1013-1023

Lechowicz MJ, Koike T (1995) Phenology and seasonality of woody plants: an unappreciated element in global change research? Can J Bot 73:147-148

Leinonen I, Kramer K (2002) Applications of phenological models to predict the future carbon sequestration potential of boreal forests. Clim Change 55:99-113

Lenihan JM, Drapek R, Bachelet D, Neilson RP (2003) Climate change effects on vegetation distribution, carbon, and fire in California. Ecol Appl 13:1667-1681

Lenihan JM, Bachelet D, Neilson RP, Drapek R (2008) Response of vegetation distribution, ecosystem productivity, and fire to climate change scenarios for California. Clim Change 87:215-230

Lieth H (1974) Phenology and seasonality modeling. Springer-Verlag, Berlin

Linsley-Noakes G, Louw M, Allan P (1995) Estimating daily positive Utah chill units using daily minimum and maximum temperatures. J SA Soc Hort Sci 5:19-23

Maurer C, Hammerl C, Koch E, Hammerl T, Pokorny E (2011) Extreme grape harvest data of Austria, Switzerland and France from AD 1523-2007 compared to corresponding instrumental/reconstructed temperature data and various documentary sources. Theor Appl Climatol 106:55-68

Menzel A (2005) A 500 year pheno-climatological view on the 2003 heatwave in Europe assessed by grape harvest dates. Meteorol Zeits 14:75-77

Menzel A, Estrella N, Fabian P (2001) Spatial and temporal variability of the phenological seasons in Germany from 1951 to 1996. Glob Change Biol 7:657-666

Morin X, Viner D, Chuine I (2008) Tree species range shifts at a continental scale: new predictive insights from a process-based model. J Ecol 96:784-794

Morin X, Lechowicz MJ, Augspurger C, O'Keefe J, Viner D, Chuine I (2009) Leaf phenology in 22 North American tree species during the 21st century. Glob Change Biol 15:961-975

Moritz C, Patton JL, Conroy CJ, Parra JL, White GC, Beissinger SR (2008) Impact of a century of climate change on small-mammal communities in Yosemite National Park, USA. Science 322:261-264

Murray MB, Cannell MGR, Smith RI (1989) Date of budburst of fifteen tree species in Britain following climatic warming. J Appl Ecol 26:693-700

Myking T (1997) Effects of constant and fluctuating temperature on time to budburst in Betula pubescens and its relation to bud respiration. Trees 12:107-112

Nee CC (1994) The effects of continuous rainings on the fruit set of kiwifruit (Actinidia deliciosa (A. Chev.) C. F. Lianf et A. R. Ferguson) in the highland of Taiwan. J Chin Soc Hort Sci 40:282-286

Nee CC, Lin WB, Hummer K (1995) The Recovery of Taiwan Native Pear (Pyrus koehnei Schneider) (III)-growth characteristics. J Chin Soc Hort Sci 41:107-115

Nienstaedt H, Olson JS (1961) Effects of photoperiod and source on seedling growth of eastern hemlock. For Sci 7:81-96

O'Neill BF, Caffarra A, Gleeson E, Semmler T, McGrath R, Donnelly A (2010) The use of climate projections in the modelling of bud burst. EGU General Assembly Conference Abstracts, 15011, vol 12

Ou SK, Hwang MF, Li CP, Lu SJ, Song CW (2000) The relationship between cultivar's chilling requirement and planting altitudes of peaches. J Agric Res China 49:46-53

Parmesan C, Yohe G (2003) A globally coherent fingerprint of climate change impacts across natural systems. Nature 421:37-42

Pauli H, Gottfried M, Grabherr G (2014) Effects of climate change on the aloine and nival vegetation. J Mount Eco 7:9-12

Peñuelas J, Filella I (2001) Responses to a warming world. Science 294:793-795

Perry TO (1971) Dormancy of trees in winter. Science 171:29-35

Phillips SJ, Dudík M, Schapire RE (2004) A maximum entropy approach to species distribution modeling. In: Proceedings of the twenty-first international conference on Machine learning, pp. 655-662

Pimm SL, Jenkins CN, Abell R, Brooks TM, Gittleman JL, Joppa LN, Raven PH, Roberts CM, Sexton JO (2014) The biodiversity of species and their rates of extinction, distribution, and protection. Science 344(6187):987-997

Piper EL, Boote KJ, Jones JW, Grimm SS (1996) Comparison of two phenology models for predicting flowering and maturity date of soybean. Crop Sci 36:1606-1614 
Prentice IC, Sykes MT, Cramer W (1993) A simulation model for the transient effects of climate change on forest landscapes. Ecol Model 65:51-70

Raschke K (1960) Heat transfer between the plant and the environment. Annu Rev Plant Phys 11:111-126

Reich PB, Borchert R (1984) Water stress and tree phenology in a tropical dry forest in the lowlands of Costa Rica. J Ecol 72:61-74

Renton M, Childs S, Standish R, Shackelford N (2013) Plant migration and persistence under climate change in fragmented landscapes: does it depend on the key point of vulnerability within the lifecycle? Ecol Model 249:50-58

Richardson AJ, Seeley SD, Walker DR (1974) A model for estimating the completion of rest for 'Redhaven' and 'Elberta' peach trees. HortScience 9:331-332

Robak H, Magnesen S (1970) Contribution to the knowledge of the ecology of growth termination in spruce seedlings of Norwegian and Central European provenances. Silvae Genet 19:188-190

Robertson GW (1968) A biometeorological time scale for a cereal crop involving day and night temperatures and photoperiod. Int J Biometeorol 12:191-223

Rode KD, Amstrup SC, Regehr EV (2010) Reduced body size and cub recruitment in polar bears associated with sea ice decline. Ecol Appl 20:768-782

Root TL, Price JT, Hall KR, Schneider SH, Rosenzweig C, Pounds JA (2003) Fingerprints of global warming on wild animals and plants. Nature 421:57-60

Running SW, Hunt ER (1993) Generalization of a forest ecosystem process model for other biomes, BIOME-BGC, and an application for globalscale models. In: Ehleringer JR, Field CB (eds) Scaling physiological processes: leaf to globe. Academic Press, New York, pp 141-158

Sanders CG (1975) Comments on the model for estimating the completion of rest for "Red Haven" and "Elberta" peach trees. Hortic Sci 10:560-561

Sarvas R (1974) Investigations on the annual cycle of development of forest trees 2: autumn dormancy and winter dormancy. Communicationes Instituti Forestalis Fenniae 76:1-110

Schnelle F (1955) Pflanzen-Phänologie. Akademische Verlagsgesellschaft, Leipzig

Schwartz MD (1997) Spring index models: an approach to connecting satellite and surface phenology. In: Lieth H, Schwartz MD (eds) Phenology in seasonal climates. Backhuys, Leiden, pp 23-38

Schwartz MD, Marotz GA (1986) An approach to examining regional atmosphere-plant interactions with phenological data. J Biogeogr 13:551-560

Schwartz M, Marotz G (1988) Synoptic events and spring phenology. Phys Geogr 9:151-161

Sitch S, Smith B, Prentice IC, Arneth A, Bondeau A, Cramer W, Kaplan JO, Levis S, Lucht W, Sykes MT (2003) Evaluation of ecosystem dynamics, plant geography and terrestrial carbon cycling in the LPJ dynamic global vegetation model. Glob Change Biol 9:161-185

Song CW, Ou SK (1997) Thermal time required for fruit development in lowchill peaches. J Agric Res China 46:42-50
Sparkes TH, Carey PD, Coombes J (1997) First leafing dates of trees in Surrey between 1947 and 1996. Lond Nat 76:15-20

Stearns F, Olson J (1958) Interactions of photoperiod and temperature affecting seed germination in Tsuga canadensis. Am J Bot 45:53-58

Telewski FW (1995) Wind-induced physiological and developmental responses in trees. In: Coutts MP, Grace J (eds) Wind and trees. Cambridge University Press, Cambridge, pp 237-263

Thuiller W (2003) BIOMOD-optimizing predictions of species distributions and projecting potential future shifts under global change. Glob Change Biol 9:1353-1362

Tissue DT, Wright SJ (1995) Effect of seasonal water availability on phenology and the annual shoot carbohydrate cycle of tropical forest shrubs. Funct Ecol 9:518-527

van Leeuwen WJD, Casady GM, Neary DG, Bautista S, Alloza JA, Carmel Y, Wittenberg L, Malkinson D, Orr BJ (2010) Monitoring post-wildfire vegetation response with remotely sensed time-series data in Spain, USA and Israel. Int J Wildland Fire 19:75-93

van Mantgem PJ, Stephenson NL, Byrne JC, Daniels LD, Franklin JF, Fulé PZ, Harmon ME, Larson AJ, Smith JM, Taylor AH (2009) Widespread increase of tree mortality rates in the western United States. Science 323:521-524

Vegis A (1964) Dormancy in higher plants. Annu Rev Plant Phys 15:185-224

Villalta O, Holmes R, Kreidl S, Partington D, Hodson A, Atkins TA (2007) A weather-based model implemented in HortPlus MetWatch with potential to forecast brown rot infection risk in stone fruit. Acta Horticulturae 803:19-28

Vitasse Y, François C, Delpierre N, Dufrêne E, Kremer A, Chuine I, Delzon S (2011) Assessing the effects of climate change on the phenology of European temperate trees. Agr For Meteorol 151:969-980

Walker MD, Ingersoll RC, Webber PJ (1995) Effects of interannual climate variation on phenology and growth of two alpine forbs. Ecology 76:1067-1083

Wareing PF (1956) Photoperiodism in woody plants. Annu Rev Plant Phys 7:191-214

Watsona RA, Gabrielle BN, Traceya SR, Fultond EA, Bulmand CM, Edgara GJ, Barretta NS, Lylea JM, Frushera SD, Buxton CD (2013) Ecosystem model of Tasmanian waters explores impacts of climate-change induced changes in primary productivity. Ecol Model 264:115-129

Yiou P, de Cortázar-Atauri IG, Chuine I, Daux V, Garnier E, Viovy N, Leeuwen CV, Parker A, Boursiquot JM (2012) Continental atmospheric circulation over Europe during the Little Ice Age inferred from grape harvest dates. Clim Past 8:577-588

Zhao M, Peng C, Xiang W, Deng X, Tian D, Zhou X, Yu G, He H, Zhao Z (2013) Plant phenological modeling and its application in global climate change research: overview and future challenges. Environ Rev 21:1-14

Zottele F, Caffarra A, Gleeson E, Donnelly A (2011) Mapping future phenology of birch in Ireland. European GeoSciences Union General Assembly 2011:EGU2011-12307-3

Zou XM (1983) Agricultural phenology. Agricultural Press, Beijing

\section{Submit your manuscript to a SpringerOpen ${ }^{\circ}$ journal and benefit from:}

- Convenient online submission

- Rigorous peer review

- Immediate publication on acceptance

- Open access: articles freely available online

- High visibility within the field

- Retaining the copyright to your article

Submit your next manuscript at $>$ springeropen.com 